\title{
DOS DILEMAS JUDICIALES EN RONALD DWORKIN*
}

\author{
Óscar Alexis Agudelo Giraldo \\ Universidad Católica de Colombia
}

\section{Resumen}

Desde disciplinas jurídicas contemporáneas como la teoría de la argumentación jurídica sobresale el trato de los denominados casos difíciles como asunto de metodología. Así, tras afrontar nociones formalistas y antiformalistas del Derecho, la tradición jurídica de Occidente no ha logrado responder de manera unívoca a la solución de los casos difíciles. En la práctica del Derecho sobresalen por su complejidad casos constitucionales difíciles, cuyo tratamiento no estriba en el procedimiento mecanicista de la decisión judicial, frente a lo que sobresalen disciplinas auxiliares como la Tópica Jurídica, de Viehweg y el uso de los razonamientos dialécticos ante a los casos constitucionales difíciles. Como lo pensó Dworkin, lo anterior supone que persiste una actividad filosófica en la función judicial, al menos respecto a la solución de los casos difíciles.

Palabras clave: decisión judicial, casos constitucionales difíciles, teorías semánticas de la interpretación, tópica, razonamiento dialéctico.

El autor: magíster en Filosofía del Derecho y Teoría Jurídica. Docente investigador adscrito al Grupo de Estudios Legales y Sociales Phronesis, del Centro de Investigaciones Socio-Jurídicas de la Facultad de Derecho, Universidad Católica de Colombia. Correo electrónico: oaagudelo@ucatolica.edu.co

Recibido: 21 de junio de 2013; evaluado: 12 de septiembre de 2013; aceptado: 25 de noviembre de 2013.

Este artículo se estructura como desarrollo del proyecto de investigación "Conceptuadores operativos en el orden del derecho", del Grupo de Estudios Legales y Sociales Phronesis, adscrito al Centro de Investigaciones Socio-Jurídicas (Cisjuc) de la Facultad de Derecho, Universidad Católica de Colombia. 


\title{
TWO LEGAL DILEMMAS \\ IN RONALD DWORKIN
}

\author{
Óscar Alexis Agudelo Giraldo \\ Universidad Católica de Colombia
}

\begin{abstract}
From contemporary legal disciplines like the Theory of Legal Argumentation, the treatment of the so-called hard cases stand out as a matter of methodology. Thus, after confronting formalist and anti-formalist notions of Law, the Western legal tradition has not been able to respond univocally to the solution of hard cases. In the practice of Law, difficult constitutional cases stand out for their complexity, which treatment does not lie in the mechanical procedure of legal decision, in contrast to auxiliary disciplines such as Viehweg's Legal Topic and the use of dialectical reasoning before difficult constitutional cases. As Dworkin stated, the former assumes that a philosophical activity persists in the legal function, at least regarding the solution of hard cases.
\end{abstract}

Keywords: Legal decision, difficult constitutional cases, semantic theories of interpretation, topic, dialectical reasoning.

About the author: Master in Philosophy of Law and Legal Theory. Researcher and professor assigned to the Legal Studies and Social Phronesis Group at the Socio-Legal Research Center (Cisjuc by its initials in Spanish) from the Universidad Catolica de Colombia Faculty of Law. E-mail: oaagudelo@ucatolica.edu.co

Received: June 21, 2013; reviewed: September 12, 2013; accepted: November 25, 2013 


\section{Introducción}

Al cabo de cuarenta años de vida académica, la literatura de Dworkin es abundante. Después de su fallecimiento hay alrededor de doscientos escritos entre libros, artículos y ensayos. Su obra se mueve en tres áreas de fundamentación teórica, seguidas cronológicamente: i) La teoría del Derecho; ii) La teoría de la justicia y la teoría política, y iii) La teoría de la moral y la ética. En la teoría jurídica de Ronald Dworkin sobresalen ejes temáticos como la defensa de los derechos individuales en contra de la visión utilitarista del Derecho, la noción de integralidad de los sistemas jurídicos que articula las reglas con los principios, a fin de evitar el margen de discrecionalidad judicial y, como desarrollo temático póstumo, se vislumbra el problema relativo a los desacuerdos en el Derecho. De esta forma, pese a haber sido un jurista procedente de la tradición del Derecho anglosajón, es ostensible que centrara su preocupación teórica en los problemas de la práctica judicial, en la que, al denunciar la existencia de juicios morales e ideología en la interpretación y decisión judicial, combina y articula sus tres enfoques teóricos.

El 11 de octubre de 2000, Ronald Dworkin fue homenajeado en la ciudad de Nueva York con el premio "Scholar of the Year". Frente a un prestigioso auditorio de abogados pertenecientes a grandes firmas, presentó un artículo titulado “¿Deben nuestros jueces ser filósofos? ¿Pueden ser filósofos?”, que contenía dos dilemas en la decisión judicial frente a los casos constitucionales difíciles y se basó en la posibilidad de exigir a los jueces una formación suficiente en filosofía, pues, en el entender de Dworkin, los jueces constitucionales comparten la metodología de los filósofos.

En el presente escrito se analizará la viabilidad de los dos dilemas judiciales ante el ejercicio filosófico y se esbozan algunos de los planteamientos de la teoría jurídica y la teoría moral en Ronald Dworkin y su conexidad con los postulados de la teoría jurídica de Robert Alexy.

\section{Primer dilema: ¿deben los jueces ser filósofos?}

En su quehacer jurídico, los jueces, al igual que los filósofos, parten de problemas sobre asuntos que son objeto de consideración no solo de la literatura jurídica, sino además de la literatura filosófica. Muestra de ello, problemas de índole filosófica y jurídica como la determinación del concepto de persona y existencia de la misma, 
la demarcación del criterio de igualdad y la autonomía individual como postulado desarrollado por la filosofía que figura como límite a mecanismos jurídicos como el paternalismo estatal entre otros. A manera de ejemplo, Dworkin plantea que, cuando el juez trata de elevar un juicio de responsabilidad frente a un daño causado, dicho juicio sugiere el análisis de dos conceptos filosóficos: el de responsabilidad y el de nexo causal. ${ }^{1}$

Para Dworkin, es claro que los asuntos filosóficos cobran mayor trascendencia en el Derecho Constitucional bajo la decisión de casos difíciles, los cuales suponen interpretaciones morales, por ejemplo, decisiones judiciales dramáticas respecto al aborto, al suicidio asistido, a la libertad de expresión y a los derechos de las parejas del mismo sexo, entre otros. La decisión de los casos difíciles sitúa el núcleo del debate entre el profesor Dworkin y el profesor Hart, pues en la tesis de Hart hay lugar a discrecionalidad judicial en cuanto a casos difíciles, mientras en Dworkin, dada la existencia de principios como elemento de integralidad, no hay lugar a ella.

La posibilidad de existencia de casos difíciles se vislumbra con mayor claridad en los casos que afronta el Derecho Constitucional. En relación con las bases del debate teórico jurídico entre Hart y Dworkin, se presentan casos difíciles cuando operan dos o más alternativas de solución al problema jurídico planteado, por lo que resulta casi imposible determinar cuál de las alternativas de solución equivaldría a la decisión judicial correcta. ${ }^{2}$ De ahí que frente a una decisión judicial opere una pretensión de corrección material, tendiente a determinar cuál hubiese sido la respuesta jurídica más correcta al problema jurídico planteado. ${ }^{3}$

En su mayoría, los casos difíciles surgen por problemas semánticos y de definición de terminología jurídica, es decir, por normas jurídicas que soportan textura abierta, dado el alto grado de vaguedad de los conceptos empleados en la formulación lingüística de la norma jurídica. En este punto, por tratarse los casos difíciles por problemas semánticos, el juez opera de forma indirecta como juez y filósofo, puesto que en la solución al caso deberá dar razones por las cuales determina un significado específico al o a los términos que hacen de la norma jurídica una norma

Ronald Dworkin, “¿Deben nuestros jueces ser filósofos? ¿Pueden ser filósofos?”, Isonomía Revista de Teoría Jurídica y Filosofía del Derecho 32, núm. (2010): 8.

2 César Rodríguez, La decisión judicial. El debate Hart-Dworkin (Bogotá: Siglo del Hombre editores, 2002), 68.

3 Robert Alexy, Teoría de la argumentación jurídica (Madrid: Centro de estudios político y constitucionales, 2007), 208. 
de textura abierta; por lo tanto, la solución a los casos difíciles es una solución de definiciones jurídicas.

César Rodríguez presenta otros tipos de casos difíciles, cuyo origen no deriva de la textura abierta de la norma jurídica o vaguedad de sus expresiones lingüísticas:

i) Hay lugar a un caso difícil cuando, en la solución aplicable al problema jurídico, hay dos principios que colisionan. Debe entenderse que la colisión de dos principios como tipo de caso difícil no reporta las mismas características ni arroja iguales consecuencias que la contradicción entre dos normas jurídicas. ${ }^{4}$ En el procedimiento de ponderación de derechos fundamentales en categoría de principios se encuentra que entre los principios no operan contradicciones sino colisiones ${ }^{5}$ y en la determinación del peso concreto de cada uno de los principios, en apoyo de unas cargas argumentativas, se determina cuál derecho tiene más peso en el problema jurídico planteado sin que esto conlleve a que el principio derrotado desaparezca del sistema jurídico. ${ }^{6}$

A su vez, esta forma de caso difícil apoyado en principios demuestra con mayor profundidad la carga filosófica en la decisión judicial, pues elegir un derecho fundamental sobre otro requiere, como tercer paso, la ponderación de una carga argumentativa; en este paso habrá lugar a argumentos de índole filosófica y teórica por parte del juez que apoyen su decisión y la elección del principio en cuestión. No sobra advertir en este punto que, frente a los casos difíciles de colisión de principios en sede de derechos fundamentales, en su decisión el juez constitucional podría llegar a alterar el contenido esencial de los principios o derechos fundamentales en colisión, con lo que se afecta el modelo de rigidez constitucional. ${ }^{7}$

ii) Otro tipo de caso difícil sería aquel en donde no existe siquiera una solución jurídica normativa al problema planteado; esto da lugar a la presencia de una laguna normativa. Este tipo de caso difícil puede surgir en virtud de la relativa

\footnotetext{
Rodríguez, La decisión judicial, 68.

5 De ahí que los científicos del Derecho determinen, para el caso de colisión de dos derechos fundamentales, el término "conflictivismo". Óscar Alexis Agudelo Giraldo, "Restricción, limitabilidad y derechos fundamentales" en Crítica y fundamentación de la politica y los derechos humanos, comp. Elías Castro Blanco (Bogotá: Ediciones Universidad Libre, 2012), 146-166.

- Carlos Bernal Pulido, "La ponderación como procedimiento para interpretar los derechos fundamentales", en Problemas contemporáneos de la filosofía del derecho, coord. Enrique Cáceres, Imer Flores, Javier Saldaña, Enrique Villanueva (México, Universidad Nacional Autónoma de México, 2005), 21.

Agudelo, "Restricción, limitabilidad", 158.
} 
"indeterminación de propósitos del legislador", pues en la determinación de propiedades jurídicas relevantes en la elaboración de normas jurídicas no es factible exigir al legislador una predicción de lo que pueda ocurrir y, por lo tanto, deba legislar.

iii) Hay lugar a un caso difícil cuando, a pesar de que existe solo una alternativa de solución al caso, su aplicación es injusta, según el criterio del intérprete. Aquí subyace toda una teoría de las normas injustas y la hipótesis de no obligación por parte de los jueces de aplicación de estas normas. Esta forma de casos difíciles demuestra la cercanía de las decisiones judiciales con asuntos temáticos y metodológicos de la filosofía. La doctrina de la ley injusta aparece en el mundo del Derecho por medio de decisiones judiciales históricas respecto a problemas jurídicos que constituyeron evidentes casos difíciles, al tener que juzgar y decidir sobre hechos del pasado que fueron amparados en una normatividad jurídica injusta, pero válida, de acuerdo con los presupuestos temporales de validez de cada Nación. Un ejemplo clásico ocurrió en los famosos juicios de Nuremberg, en los que los jueces de las Naciones vencedoras juzgaron a los soldados alemanes por las atrocidades cometidas durante el holocausto nazi; con la advertencia de que los hechos cometidos estaban cobijados por la normatividad alemana de la época, declararon a su favor que sus acciones, a pesar de ser atroces, no fueron contrarias al Derecho de su época. Otro ejemplo se presentó en una famosa sentencia del Tribunal Constitucional alemán, denominada "Mauerschutzen", la cual condenó a varios soldados alemanes que, bajo la legislación de la República Democrática Federal Alemana, estaban facultados para disparar en contra de quienes intentaran traspasar las fronteras de ese país y mataron un sinnúmero de ciudadanos alemanes.

Ley de fronteras de la RDA, año 1982, parágrafo 27, apartado 2, párrafo 1: El uso de armas de fuego está justificado para evitar la perpetración inminente o la continuación de un hecho delictivo que tenga la apariencia de delito según las circunstancias [...]. Parágrafo 27, apartado 5: Al hacer uso de las armas de fuego se protegerá en lo posible la vida de las personas. ${ }^{8}$

Óscar Pérez de la Fuente, "El caso de los tiradores del muro de Berlín. A vueltas con algunos debates clásicos de la Filosofía del Derecho del siglo XXI", Cuadernos electrónicos de Filosofía del Derecho 1, núm. 23 (2011): 454. 
Años más tarde, ese mismo Tribunal juzgó a aquellos centinelas alemanes que, pese a estar justificados por la ley, fueron condenados; para ello, usó la fórmula del "Derecho extremadamente injusto", de Gustav Radbruch, que, para los funcionarios encargados de aplicar las leyes hace, torna inconveniente la utilización y aplicación de las leyes de un Estado injusto o las leyes injustas de un Estado.

He aquí otro punto en el que la historia muestra su apoyo a la tesis de Dworkin, pues la solución a un caso difícil que devenía de una normatividad injusta tuvo fundamento en la determinación del concepto "Derecho injusto" y "norma injusta"; para este caso, ambas definiciones usadas por los jueces del Tribunal Constitucional fueron determinadas desde la Filosofía por filósofos del Derecho. Esto obligó a los jueces de la época a desentrañar un concepto filosófico para determinar el alcance de su decisión judicial.

Parece vislumbrarse que el quehacer filosófico de los jueces opera en asuntos trascendentales como los relativos a derechos fundamentales, en cuya colisión subyace una serie de cuestiones epistemológicas y filosóficas presentes en cada uno de estos casos difíciles.

En términos actuales, otra alternativa de clasificación y definición de casos fáciles y difíciles se basa en la posibilidad de justificar cada uno de estos en lo jurídico. En la teoría de la argumentación jurídica, en sede de motivación de las decisiones judiciales persiste, más allá del silogismo jurídico presentado en las tesis formalistas del siglo XX, una justificación de las premisas fácticas y normativas del raciocinio jurídico o silogismo judicial. De esta manera, se está en presencia de un caso fácil cuando ambas premisas del razonamiento son notoriamente identificables, es decir, frente a la justificación de la premisa normativa como asunto de interpretación: "Existe un amplio consenso entre los juristas acerca de cuál o cuáles son las normas aplicables", mientras que, frente a la premisa fáctica del silogismo judicial, un caso resulta fácil cuando es ostensible y la calificación jurídica sobre los hechos del caso y su adecuación con una consecuencia normativa no dan lugar a dudas. ${ }^{9}$ En cambio, habrá lugar a casos difíciles en materia de argumentación jurídica cuando no sea posible seguir de manera mecánica la deducción del silogismo jurídico y se afecte la justificación de las premisas fáctica y normativa.

9 David Martínez Zorrilla, Metodología jurídica y argumentación (Madrid: Marcial Pons, 2010), 33. 
Dworkin plantea una serie de ejemplos relativos a derechos fundamentales, cuya solución no estriba en la interpretación mecánica de normas jurídicas, sino de una reflexión filosófica en la práctica judicial. Cuestiona que si los problemas que afronta un juez han sido debatidos por personas educadas, este debería ignorar lo que se ha escrito. Algunos de aquellos ejemplos son:

¿Un feto es una persona de derechos? ¿Constituye una violación a la igualdad el hecho de tratar de forma diferente a aquellos aspirantes a universidades que ingresan por su habilidad para el baloncesto? ¿El hecho de que los ciudadanos tengan un derecho a la independencia moral en sus decisiones significa que la manera como deben morir es su decisión personal? ${ }^{10}$

Con la formulación de estas preguntas Dworkin trata de demostrar que no pueden ser solucionadas por la ciencia, la economía o la historia, pero dado que en cada uno de estos casos se presenta una confrontación de valores, su solución implica una correcta aplicación de los principios. De allí que considere Dworkin que jueces y filósofos no solo comparten temáticas, sino que también cuentan con objetivos y métodos comunes. Por ello: "Ambas profesiones apuntan, más exactamente a formular y entender mejor los conceptos claves en los cuales se expresan nuestra moralidad política y nuestra Constitución". ${ }^{11}$

\section{Segundo dilema: ¿pueden los jueces ser filósofos?}

Dworkin plantea que parecería absurdo exigirles a los jueces un pregrado en Filosofía, si se tiene en cuenta que se desearía que los fallos fuesen formulados en lenguaje general y asequible, no en lenguaje filosófico. Por ello:

El clare loqui o hablar claro es un imperativo procesal implícito en la redacción de las resoluciones judiciales, de modo que estas deben emplear un lenguaje asequible a los intervinientes en el proceso, evitando proposiciones oscuras, vagas, ambiguas o imprecisas. Muchas veces, el lenguaje judicial se presenta como algo esotérico u oculto para los justificables, olvidándose que es a ellos a quienes va dirigido. ${ }^{12}$

Dworkin, "¿Deben nuestros jueces ser filósofos?", 09

Dworkin, "¿Deben nuestros jueces ser filósofos?", 9.

José Luis Castillo, Manuel Luján y Roger Zavaleta Rodríguez, Razonamiento judicial. Interpretación, argumentación y motivación de las resoluciones judiciales (Bogotá: Ara editores, 2007), 464. 
De esta manera, Dworkin presenta la fórmula del dilema:

"Los jueces tienen que ser filósofos, pero no pueden y quizás no deben ser filósofos". ${ }^{13}$

A manera de antítesis, el autor presenta dos posibles rutas de escape que serán resumidas en tres tesis a las cuales llamará "ilusiones".

La fórmula de la ruta de escape dice: "No es verdad que los jueces tengan que ser filósofos y tampoco es verdad que no puedan serlo, solo deben ser lo suficientemente filósofos". ${ }^{14}$

Las antítesis que presenta Dworkin frente a su pretensión parten de las siguientes objeciones basadas en "Los conceptos, la historia y la intención original".

\section{Objeción de los conceptos}

Es evidente que, sin riesgo alguno, los jueces pueden ignorar la Filosofía, dado que los problemas jurídicos como casos difíciles relativos a la textura abierta de las normas jurídicas se refieren a conceptos jurídicos distintos a los conceptos del lenguaje ordinario de los filósofos. Parece que la carga de tecnicismo en la formulación de las normas jurídicas es algo inevitable. Sin embargo, como objeción a la ignorancia de conceptos filosóficos en la práctica judicial y en la formulación lingüística de normas jurídicas, Dworkin destaca que, al llevar a la práctica conceptos como igualdad y libertad -ligados tradicionalmente a la idea por parte de la ciudadanía de igual trato frente a la ley-, desarrollan principios morales cuya formulación lingüística, antes que jurídica, es filosófica. Basta ver para ello las extensas disertaciones filosóficas en torno a la libertad e igualdad, que preceden y determinan su concepto jurídico. ${ }^{15}$

Sin embargo, dado su obligatorio acatamiento en la práctica judicial, se encuentra que los precedentes configuran el significado de los términos jurídicos y limitan la capacidad de los jueces para efectuar nuevas compresiones. Mas, debido a la dinámica de los sistemas jurídicos, hay nuevos casos que suponen nuevos conceptos, en cuyo caso los jueces seguirán sus propios criterios, que pueden versar sobre argumentos filosóficos o de teoría política. Por ejemplo, dice Dworkin que

\footnotetext{
Dworkin, “¿Deben nuestros jueces ser filósofos?", 11.

Dworkin, “¿Deben nuestros jueces ser filósofos?", 11.

15 Dworkin, “¿Deben nuestros jueces ser filósofos?”, 11.
} 
preguntarse si el derecho de libertad de expresión protege el lenguaje cargado de odio hacia minorías perseguidas requiere un planteamiento básico de asuntos de moralidad política. ${ }^{16}$

\section{La objeción de la historia y la intención original}

Adicional a la objeción de los conceptos, Dworkin muestra la objeción de la historia y la intención original, según la cual los jueces no deben buscar la mejor postura filosófica que aborde y defina el concepto jurídico tratado, sino descubrir la mejor teoría de quienes propusieron tales ideas en el pensamiento jurídico; esto es una cuestión histórica o de la intención original del autor, lo que en términos jurídicos equivale a indagar la intención de aquel que formuló la expresión vaga dentro de la norma jurídica. Este punto fue un foco de debate en el Derecho estadounidense entre el profesor Hart y el profesor Lon Fuller. Tal debate parte de la delimitación del criterio según el que debe indagarse por el significado de las expresiones lingüísticas vagas presentes en la formulación de normas jurídicas. Un ejemplo fue la determinación, por parte del profesor Hart, de una hipotética norma jurídica x que señalaba: "Se prohíbe la circulación de vehículos en los parques", donde el término "vehículo" demostraba la textura abierta de la norma en cuestión. La respuesta de cada uno de los autores equivale a un modo específico de interpretación de normas jurídicas. Jorge Cerdio Herrán resume el modelo del profesor Fuller, que pretenderá desentrañar la "intención general" que subyace bajo el término en cuestión. Su fórmula silogística se presenta así:

1. El significado de las reglas jurídicas está en función del significado del lenguaje.

2. El significado de las reglas jurídicas está en función del propósito de emisor (inferencia inmediata). ${ }^{17}$

Luego, de la relación entre (1) y (2), concluye el profesor Fuller que la aplicación de las reglas jurídicas está en función de su significado y, por ello, la claridad de un caso en cuestión dependerá de la identificación del propósito del emisor. ${ }^{18}$

Dworkin, “¿Deben nuestros jueces ser filósofos?”, 14

Jorge Cerdio Herrán. "A propósito de Fuller y el uso lingüístico" (ponencia presentada en XVI Jornadas argentinas de Filosofía jurídica y social, Buenos Aires, 24-26 octubre, 2002), 3.

18 Cerdio Herrán, "A propósito de Fuller", 3. 
La respuesta de Hart al modelo de Fuller atenderá a la definición de un término que acompaña la formulación de una norma jurídica, según el uso que se otorga al término en cuestión. Como silogismo se resumiría así:

a. Conocer el significado de la regla jurídica es ser capaz de identificar los casos típicos en los que la regla se aplica.

b. La aplicación de las reglas jurídicas está en función del significado de las reglas jurídicas.

c. La aplicación de las reglas jurídicas está en función del uso de las expresiones lingüísticas que las expresan.

Del seguimiento de las premisas del modelo del profesor Hart se concluye que cuando se comprende el significado de las reglas jurídicas y se encuentran los casos típicos a los cuales se aplica, se está en presencia de un caso fácil. ${ }^{19}$

En los dos modelos presentados es claro que hay una disputa relativa a los criterios de uso, según los cuales un término se aplica o no a casos típicos particulares. En El imperio de la justicia Dworkin demuestra que la postura del realismo jurídico anglosajón frente a las propuestas de Hart y Fuller se encontraba permeada por un "aguijón semántico". El problema es que, a juicio de Dworkin, este tipo de disputas es verbal, mas no genuino, pues en desacuerdos como los de los autores el contenido es el criterio de uso y la significación de las expresiones que constituyen la disputa misma. Un desacuerdo genuino partiría de una misma base frente al criterio de uso. De esta manera, un debate verbal y no genuino por tratarse de discutir el criterio de uso del término redundaría hasta en la definición del término "Derecho". De ahí que:

El derecho no puede florecer como una empresa interpretativa en cualquier comunidad a menos que exista un acuerdo inicial suficiente sobre cuáles son las prácticas legales de modo que los abogados discuten sobre la mejor interpretación de lo que, a grandes rasgos, es la misma idea. ${ }^{20}$

Así entiende Dworkin que deben abandonarse las teorías semánticas de la interpretación, por lo que "Para que una disputa sea considerada genuina, los términos

19 Cerdio Herrán, "A propósito de Fuller", 5.

20 Ronald Dworkin, El imperio de la justicia, (Barcelona: Gedisa, 2012), 74 
en los que se formulan las posiciones enfrentadas deben significar lo mismo para cada uno de los contendientes". ${ }^{21}$ Respecto a los casos constitucionales, si se abandona el aguijón semántico, todo participante del debate debe estar en capacidad de reconocer los "casos centrales de aplicación de un término". ${ }^{22}$

Luego de desentrañar el problema de los desacuerdos interpretativos y semánticos, los últimos años de la teoría jurídica de Dworkin se sitúan más allá del debate de la discrecionalidad judicial. El nuevo dilema implica que la práctica del Derecho responde a los desacuerdos entre juristas y que interpretar es su verbo rector. En cuanto a la interpretación de los textos constitucionales, Dworkin estima la interpretación basada en el originalismo; dicha posición equivale a indagar por las intenciones de quienes redactaron o crearon una norma de carácter constitucional, es decir, lo que los ancestros estimaron que debía regular la norma jurídica. Esta posición se enfoca en el debate entre constitucionalismo y democracia, donde el constitucionalismo, por medio de la fórmula del precompromiso, adoptará una posición originalista ante la interpretación de normas jurídicas ambiguas como las de derechos fundamentales.

En cuanto al originalismo persisten dos ramificaciones:

i) Un originalismo semántico, que alude a "lo que querían decir los legisladores" como punto definitivo en la asignación de significado a los textos constitucionales.

ii) Un originalismo de expectativa, que atiende a lo que esperaban conseguir los fundadores o redactores originales a partir de lo dicho. ${ }^{23}$

Sin embargo, la tesis del originalismo yerra si el legislador estimó cláusulas constitucionales abstractas. Es aquí donde Dworkin encuentra una presencia moral en el Derecho. De acuerdo con las tesis del positivismo jurídico incluyente, cualquier interpretación remite a cierta moralidad. ${ }^{24}$ Este postulado será combinado por Moreso con la fórmula de asignación de significado, de acuerdo con la teoría causal de la referencia, que afirma que los términos tienen una construcción histórica

\footnotetext{
Pablo Raul Bonorino, Integridad, Derecho y justicia (Bogotá: Siglo del Hombre, 2003), 48.

Pablo Raul Bonorino, Integridad, Derecho y justicia, 49.

Ronald Dworkin, Justice in Robes (Londres: Harvard University Press, 2006), 124

José Juan Moreso, Luis Prieto Sanchís y Jordi Ferrer Beltrán, Los desacuerdos en el Derecho (Madrid: Fundación

Coloquio Jurídico Europeo, 2010), 24.
} 
causal, como si tuviesen propiedades esenciales constitutivas y, a su vez, bajo la construcción causal se reporta la intención de sus creadores, lo que deja como alternativa la adopción del uso de la teoría causal o una teoría híbrida que atienda al carácter semántico de la expresión, en el contexto o intención de su creador. ${ }^{25}$

\section{Los enfoques teóricos de las dos objeciones: instinto e intuición}

Desde la perspectiva intuicionista, un juez puede resolver asuntos jurídicos que atañen a un contenido filosófico guiado por sus instintos o "por sus reacciones viscerales", en lugar de consultar las posiciones de los filósofos. De esta manera, el postulado del intuicionismo, propio del Derecho anglosajón, será: "Los jueces no deben tratar de analizar conceptos o ideas filosóficas difíciles, sino informar su reacción instintiva". Dworkin presenta como arquetipo del postulado intuicionista la figura de Oliver Wendel Holmes, quien dijo haber juzgado un procedimiento donde la Policía obtuvo evidencia con violación de la cláusula del debido proceso, bajo la simple condición de si tal procedimiento le hacía sentir náuseas. De ahí que Dworkin destaque el aforismo del realismo jurídico, según el cual "la justicia depende de lo que el juez desayunó". ${ }^{26}$

La tesis del intuicionismo parte de una noción central: "Las personas tienen facultades naturales que les permiten intuir de manera directa la verdad sobre cuestiones morales". Además, sobre el intuicionismo obra una tesis de escepticismo moral, ya que para esta no hay respuesta correcta a las cuestiones filosóficas, por ejemplo, la definición y determinación a partir de la cual se es persona y se gozan los atributos de la personalidad. ${ }^{27}$

Al respecto Dworkin presenta una objeción contundente: el problema en estas dos rutas de escape -intuicionismo y escepticismo moral- de la posibilidad de actividad filosófica en la labor judicial en casos difíciles es que los jueces deciden sobre la base de razones y, por lo tanto, las explican; de allí que una decisión instintiva no tendría justificación racional que la soporte, toda vez que las normas jurídicas surgen como el soporte de racionalidad en la decisión judicial. Asimismo, si la decisión judicial fuese tomada de manera instintiva o intuitiva, ninguno de estos modos de proceder funcionaría como fundamento en la motivación de la decisión judicial, pues la argumentación jurídica distingue dos elementos en el proceso

José Juan Moreso, Los desacuerdos en el Derecho, 25.

Dworkin, “¿Deben nuestros jueces ser filósofos?”, 17.

Dworkin, “¿Deben nuestros jueces ser filósofos?", 17. 
de toma de decisiones por parte del juez: i) Un contexto del descubrimiento que atiende al proceso psicológico y no lógico de las causas que llevan al juez a tomar una decisión judicial, momento en el que se encontrarían las decisiones judiciales instintivas, y ii) Una justificación en donde se muestran los fundamentos que dan lugar a la imposición de una decisión jurídica; estos no equivalen al ámbito psicológico del juez. ${ }^{28}$ De este modo, Dworkin articula en su concepción integral del Derecho una teoría de la argumentación jurídica situada en la fundamentación de decisiones judiciales.

\section{Pragmatismo}

Si los jueces no actúan de la mejor manera cuando contestan casos difíciles por intermedio de sus instintos inmediatos, surge la segunda ruta de escape, situada en el pragmatismo estadounidense. Pregunta si el uso de un determinado concepto filosófico en una decisión judicial, que afecta intereses colectivos, ${ }^{29}$ marca una diferencia en cuanto al futuro de la comunidad, lo cual es un ejemplo claro de la exigencia consecuencialista de las decisiones judiciales.

En vez de situarse en un debate filosófico, el pragmatismo apuesta al uso de temas prácticos que susciten las mejores consecuencias para la comunidad a largo plazo. De esta manera, se hace del Derecho una ciencia predictiva, mediante las decisiones judiciales.

La respuesta de Dworkin demuestra que la posición pragmática no confronta las otras posibles consecuencias de una decisión judicial relativa a dilemas constitucionales. El paradigma del pragmatismo legal entiende los derechos como estrategias, pero no los derechos en su sentido genuino, pues frente a la posible mejor forma de entender el futuro de una comunidad desde la decisión judicial que afecte intereses colectivos existen "derechos de las personas bien definidos", 30 es decir, existen derechos individuales o derechos de las minorías, que se presentan como límite a las decisiones que favorecen intereses colectivos o de la mayoría. Además, la

28 Manuel Atienza, Las razones del Derecho. Teorías de la argumentación jurídica (México: Universidad Nacional Autónoma de México, 2005), 4.

29 Dworkin encuentra que una decisión judicial puede presentarse bajo dos tipos de argumentos, al atender a la cantidad de destinatarios de la decisión. Una decisión judicial puede basarse en criterios cualitativos y cuantitativos de la siguiente forma: i) Por medio de un argumento de principio en el que el juez declara la protección de un derecho individual o de un grupo, y ii) Por medio de un argumento político en el que el juez favorece una "meta colectiva". Ronald Dworkin. Los derechos en serio (Barcelona: Ariel, 2002), 148.

30 Dworkin, El imperio de la justicia, 121. 
determinación de lo que es mejor para el futuro de una comunidad es una decisión que, por medio de una directriz política, le corresponde al órgano legislativo, dado que si el juez toma este rol, agrega a su adjudicación de competencia para juzgar y aplicar normas jurídicas la competencia indirecta de crearlas. Respecto a la creación judicial del Derecho, Dworkin encuentra dos objeciones básicas:

i) Los jueces no son electos de forma democrática, razón por la que no representan la voluntad popular ni son responsables frente al electorado.

ii) Si un juez legisla y al mismo tiempo aplica la ley de manera retroactiva, estaría juzgando a las personas por deberes creados después de la consumación del hecho. ${ }^{31}$

Desde la mirada integralista de Dworkin, el fenómeno de la creación judicial del Derecho muestra la presencia de lagunas y falta de claridad en las reglas; en este punto, Dworkin niega la posibilidad de creación judicial, en tanto el juez no crea reglas, pero sí resuelve casos difíciles a partir de principios. Tal tesis trae consigo la negación de la discrecionalidad. ${ }^{32}$

Dworkin, en Rodríguez, distingue tres tipos de discrecionalidad:

i) La primera ocurre cuando la labor del juez viene determinada por estándares sobre los cuales se puede razonar e interpretar de maneras diferentes.

ii) La segunda, cuando la decisión de una persona es final y definitiva y sobre ella no se admite revisión por parte de ninguna autoridad.

iii) Hay lugar a discrecionalidad fuerte cuando no hay estándares que impongan deberes en la toma de decisión judicial..$^{33}$

Resulta claro que los magistrados cuentan con una discrecionalidad de segundo tipo. En la teoría jurídica de Dworkin, habría lugar a la idea que indica que no es

Dworkin, Los derechos en serio, 150.

32 Manuel Rodríguez Puerto, "Ronald Dworkin y la creación judicial del Derecho: una reflexión breve", Anuario de Filosofía del Derecho 2, núm. 15 (1999), 125.

33 Rodríguez Puerto, "Ronald Dworkin y la creación", 126. 
cierta la inexistencia de directrices a la hora de fallar, pues existen los principios. De ahí que "incluso en los casos difíciles, el derecho no calla". ${ }^{34}$

\section{El nuevo formalismo como estrategia}

Para Dworkin, la popularidad del pragmatismo, que es una teoría vacía, demuestra la profundidad del dilema. Aquí aparece el positivismo como "una consideración inadecuada" de lo que hacen los jueces y se desatiende la idea de que las decisiones judiciales, al menos en el Derecho Constitucional, surgen como juicios sobre cuestiones morales que, a su vez, son asuntos de confrontación filosófica. La realidad lo demuestra cuando los jueces deben decidir casos difíciles en materia constitucional y determinan su enfoque a partir de principios, así quieran negarlo. De ahí que: "Es este precisamente otro ejemplo de la lamentable disposición de algunos eruditos jurídicos a ocultar sus cabezas en la arena". ${ }^{35}$

De esta forma, Dworkin alega que es hora de que el mundo del Derecho sea consciente de que los ciudadanos están divididos por asuntos o cuestiones morales y las decisiones judiciales suponen dichas cuestiones; por ello, el juez deberá justificar la posición que adopte. Sin embargo, la apuesta final de la teoría jurídica de Dworkin será la ausencia de conflicto entre el derecho a la igualdad y el derecho a la libertad, desde una tesis de la objetividad de los valores. Dworkin defiende dos posiciones que, como valores morales objetivos, integrarán su Filosofía del Derecho: "La idea del buen vivir" y "la teoría de la unidad de valor". ${ }^{36}$

Si las rutas de escape ofrecen al juez no inmiscuirse en asuntos de controversias interminables como los asuntos filosóficos, entonces aparece aquí la objeción del nuevo formalismo jurídico.

La propuesta del formalismo es evitar la existencia de casos difíciles mediante la codificación de todos los asuntos relevantes para el Derecho, de modo que la decisión judicial sea mecánica. Es un mero formalismo, pues se pretende reducir para los jueces las valoraciones y juicios sobre lo que es el Derecho. ${ }^{37}$

\footnotetext{
Rodríguez Puerto, "Ronald Dworkin y la creación", 126.

Dworkin, "¿Deben nuestros jueces ser filósofos?", 21

Germán Medardo Sandoval Trigo, "Reseña bibliográfica: Dworkin, Ronald, Justice for Hedgehogs", Problema: Anuario de Filosofía y teoría del Derecho 7, núm. 7 (2013): 220.

37 Dworkin, “¿Deben nuestros jueces ser filósofos?”, 22.
} 
El formalismo apostará por el criterio de interpretación literal u original en el caso del criterio histórico, en el que los derechos son asunto de semántica e historia, es decir, el derecho conservado como lo comprendieron sus creadores. El autor encuentra que, en el caso de la Constitución, esta no reposa en un accidente histórico, sino sobre principios.

Sin embargo, Dworkin advierte que eliminar los juicios de las reflexiones de nuestros jueces equivaldría a un retorno hacia el utilitarismo, que apuesta por la no presencia de términos morales. ${ }^{38}$

\section{Cultura jurídica y profundidad filosófica}

Desde la legislación, es ostensible que muchas veces los jueces deben decidir asuntos que han sido estudiados por diferentes filósofos e incluso desde la teoría política. Por lo tanto, deben entender que las rutas de escape o los atajos presentados no son más que ilusiones, pues tienen que elegir entre principios rivales, al menos como lo han demostrado las metodologías jurídicas empleadas en la solución de los casos difíciles.

Dicha notoriedad implica un cambio cultural que determine lo que un juez debe considerar como relevante en un argumento jurídico. Además, para un abogado es claro que debe estudiar disciplinas auxiliares "con la expectativa de encontrar argumentos útiles". Por ejemplo, dice Dworkin, en el debate de la comprensión de la cláusula de igual protección, podrían animarse el juez y los abogados a distinguir y construir concepciones de igualdad. Esto no eliminaría -pero si reduciría- la controversia entre jueces, puesto que en la reflexión filosófica es más probable un mayor número de cambios en las posturas adoptadas, además de hacer "más iluminada la controversia". ${ }^{39}$

Desde luego que la posición de Dworkin, aparte de un cambio cultural, implica mayor presencia de cátedras de introducción filosófica en los cursos jurídicos más básicos de las universidades. Por ejemplo, en la cátedra de Responsabilidad Civil Extracontractual se deberían enseñar las teorías filosóficas rivales sobre la responsabilidad moral del daño $0^{40}$ o, en el caso del Derecho Constitucional, las diversas concepciones sobre democracia; de allí que el autor encuentre que pueden ser

Dworkin, “¿Deben nuestros jueces ser filósofos?”, 24.

Dworkin, “¿Deben nuestros jueces ser filósofos?”, 27.

40 Dworkin, “¿Deben nuestros jueces ser filósofos?”, 28. 
las facultades de Derecho -incluso más que las de Filosofía- un mejor lugar para estudiar la filosofía moral y política, pues en el contexto jurídico se entienden bien "las verdaderas implicaciones de diferentes principios morales y políticos". ${ }^{41}$

\section{Conclusiones}

Es evidente que el modelo de subsunción mecanicista resulta plausible frente a casos fáciles. La aparición de los casos constitucionales difíciles supone una metodología judicial diferente, en la que sobresale, entre otros, el uso de los razonamientos dialécticos propios del quehacer de los filósofos en la construcción de un argumento útil para convencer a la mayoría del auditorio. Así, Ronald Dworkin plantea la necesidad de una mínima formación en Filosofía por parte de los funcionarios judiciales, como punto de tensión metodológico ante casos constitucionales difíciles.

\section{Referencias}

Agudelo Giraldo, Óscar. "Restricción, limitabilidad y derechos fundamentales" en Crítica y fundamentación de la politica y los derechos humanos, compilado por Elías Castro Blanco, 146-166. Bogotá: Ediciones Universidad Libre, 2012.

Alexy, Robert. Teoría de la argumentación jurídica. Madrid: Centro de Estudios Políticos y Constitucionales, 2007.

Atienza, Manuel. Las razones del Derecho. Teorías de la argumentación jurídica. México D. F: Universidad Nacional Autónoma de México, 2005.

Bernal Pulido, Carlos. "La ponderación como procedimiento para interpretar los derechos fundamentales" en Problemas contemporáneos de la filosofía del derecho, coordinado por Enrique Cáceres, Imer Flores, Javier Saldaña, Enrique Villanueva. México: Universidad Nacional Autónoma de México, 2005.

Bonorino, Pablo Raúl. Integridad, Derecho y justicia: una crítica a la teoría jurídica de Ronald Dworkin. Bogotá: Siglo del Hombre, 2003.

Castillo, José Luis, Manuel Luján Túpez y Róger Zavaleta Rodríguez. Razonamiento judicial. Interpretación, argumentación y motivación de las resoluciones judiciales. Bogotá: Ara editores, 2007.

Cerdio Herrán, Jorge. "A propósito de Fuller y el uso lingüístico". Ponencia presentada en XVI Jornadas argentinas de Filosofía Jurídica y Social, Buenos Aires, 24-26 octubre, 2002.

41 Dworkin, “¿Deben nuestros jueces ser filósofos?”, 28. 
Dworkin, Ronald. “¿Deben nuestros jueces ser filósofos? ¿Pueden ser filósofos?”. Isonomía Revista de Teoría Jurídica y Filosofía del Derecho 32, núm. 32 (2010): 7-30.

Dworkin, Ronald. El imperio de la justicia. Barcelona: Gedisa, 2012.

Dworkin, Ronald. Justice in Robes. Londres: Harvard University Press, 2006.

Dworkin, Ronald. Los derechos en serio. Barcelona: Ariel, 2002.

Martínez Zorrilla, David. Metodología jurídica y argumentación. Madrid: Marcial Pons, 2010. Moreso, José Juan, Luis Prieto Sanchís y Jordi Ferrer Beltrán. Los desacuerdos en el derecho. Madrid: Fundación Coloquio Jurídico Europeo, 2010.

Pérez de la Fuente, Óscar. "El caso de los tiradores del muro de Berlín. A vueltas con algunos debates clásicos de la filosofía del derecho del siglo XXI". Cuadernos electrónicos de Filosofía del Derecho 1, núm. 23 (2011): 453-487, http://dialnet.unirioja.es/servlet/ revista? codigo $=2494$.

Rodríguez, César. La decisión judicial. El debate Hart-Dworkin. Bogotá: Siglo del Hombre editores, 2002.

Rodríguez Puerto, Manuel. "Ronald Dworkin y la creación judicial del Derecho: una reflexión breve". Anuario de Filosofía del Derecho 2, núm. 15 (1999): 121-142.

Sandoval Trigo, Germán Medardo. "Reseña bibliográfica: Dworkin, Ronald, Justice for Hedgehogs”. Problema: Anuario de Filosofía y teoría del Derecho 7, núm. 7 (2013): 219-242. 